\title{
ANÁLISE DA CICATRIZAÇÃO DA BEXIGA COM O USO DO EXTRATO AQUOSO DA Orbignya phalerata (BABAÇU). ESTUDO CONTROLADO EM RATOS ${ }^{1}$
}

\author{
Surgical blader wounds treated with Orbignya phalerata aqueous extract: controlled study in \\ rats
}

\begin{abstract}
Eduardo de Castro Ferreira ${ }^{2}$, Jorge Eduardo F. Matias ${ }^{3}$, Antonio Carlos L. Campos ${ }^{3}$, Renato Tâmbara Filho ${ }^{3}$, Luiz Carlos de Almeida Rocha ${ }^{3}$, Jorge Rufino Ribas Timi ${ }^{3}$, Heitor Naoki Sado ${ }^{4}$, Danielle Giacometti Sakamoto ${ }^{4}$, André Ricardo D. Tolazzi ${ }^{4}$, Mario de Paula Soares Filho ${ }^{4}$
\end{abstract}

1. Trabalho realizado no laboratório de pesquisas do centro de Ciências Biológicas e da Saúde da Universidade Federal do Maranhão

2. Médico do Hospital da Universidade Federal do Maranhão

3. Professor Doutor em Cirurgia

4. Aluno de Pós-Graduação - Mestrado

5. Aluno de Pós-Graduação - Doutorado

\begin{abstract}
RESUMO
Introdução: A cicatrização constitui processo complexo, envolvendo diferentes sistemas biológicos e imunológicos, sendo essencial para manter a integridade do organismo. Três fases bem definidas ocorrem: inflamatória, proliferativa e maturação. Falha ou prolongamento em uma delas pode resultar em retardo ou ausência da cicatrização. Objetivo: Analisar comparativamente as alterações histológicas proporcionadas pelo uso do extrato aquoso da Orbignya phalerata na cicatrização de lesões cirúrgicas da bexiga. Métodos: Quarenta ratos da linhagem Wistar, adultos e machos foram utilizados. O procedimento experimental constituiu-se em incisão longitudinal de $2 \mathrm{~cm}$ na bexiga e síntese em plano único com pontos separados de poliglactina 910 cinco zeros. Após este procedimento comum, os animais foram distribuídos aleatoriamente em dois subgrupos contendo 20 animais cada. No grupo controle não foi utilizada a substância Orbignya phalerata. No grupo-experimento utilizou-se solução aquosa de Orbignya phalerata na dose de $50 \mathrm{mg} / \mathrm{kg}$ por via intraperitoneal. Os animais foram acompanhados e mortos em três e sete dias. Foi feita análise histológica comparativa entre os grupos. Resultados: Os resultados mostraram que foi observada diferença estatística significante nas variáveis neoformação ( $\mathrm{p}=$ $0,001)$ e proliferação fibroblástica $(\mathrm{p}=0,010)$ nos subgrupos controle e experimento do $3^{\circ}$ dia. Ainda no grupo experimento a neoformação capilar foi mais intensa que no grupo controle, apresentando significância estatística. No grupo de sete dias observou-se que as variáveis inflamação aguda $(p=0,001)$, inflamação crônica $(p=0,002)$ e proliferação fibroblástica $(\mathrm{p}=0,023)$ apresentaram significância estatística, sendo bem evidente a inflamação aguda no grupo controle. Conclusão: Foi observada homogeneidade no fator tempo da cicatrização nos grupos experimento e controle sendo mais rápida no grupo experimento. Houve efeito favorecedor cicatrizante na utilização do extrato aquoso do mesocarpo da Orbignya phalerata na bexiga do ratos.
\end{abstract}

Descritores: Orbignya phalerata. Cicatrização de Feridas. Bexiga. Ratos.

\begin{abstract}
Introduction: Wound healing is a complex process that deals with different biological and immunological systems and is essential to keep the organism integrity. Three well-defined phases occur: inflammatory, proliferative and maturation. A failure or lengthy phase may result in a delay or absence of it. Purpose: The aim of this paper is to analyse comparatively the histological alteration provided by the use of the aqueous extract of Orbignya phalerata, in the healing process of bladder surgical wounds. Methods: Forty adult, male Wistar rats were used. The experimental procedure consisted of a longitudinal $2 \mathrm{~cm}$ long bladder incision and single layer interrupted suture of 5-0 poliglactine 910 . Post-operatively, the rats were randomly divided into two groups of 20. The substance was not used in the control group. The Orbignya phalerata aqueous solution was used in the study group. The animals were observed and killed three and seven days later. Comparative histological analysis was accomplished between the groups. Resuts: Significant statistical differences were observed in the neo-formation variables $(p=0,001)$, chronic inflammation $(p=0,002)$ and fibroblastic proliferation $(p=$ 0,023). Acute inflammation was very evident in the control group. Conclusion: The time factor of wound healing showed homogeneity between experimental and control groups, however faster in the experimental one. The Orbignya phalerata had a favoring healing effect in the surgical incision on rats bladder.
\end{abstract}

Key Words: Orbignya phalerata. Wound Healing. Bladder. Rats. 


\section{Introdução}

A cicatrização de uma ferida cirúrgica, ou do sítio cirúrgico incisional, é fenômeno químico, físico e biológico que ocorre logo após a lesão tecidual, diferindo nas feridas abertas e fechadas ${ }^{1}$.

A manipulação dela, objetivando-se melhores resultados cicatriciais, vem desafiando os cirurgiões, cujas atitudes modificaram-se ao longo dos séculos. Numa análise panorâmica, identificam-se épocas que se caracterizam por medidas terapêuticas peculiares. Até os primórdios do cristianismo, o médico era mero espectador, e o princípio do tratamento embasava-se na interferência mínima com aplicação de toalhas limpas e mel sobre o ferimento. Aguardava-se sua resolução a custas, do que se entende atualmente, como cicatrização por segunda intenção ${ }^{2}$.

Graças às aquisições de conhecimento em metabologia cirúrgica, bioquímica e nutrição, surgiu uma nova época na qual se pretende interferir na biologia molecular, influindo na síntese das substâncias responsáveis pelo envolvimento dos fenômenos cicatriciais ${ }^{3}$.

A primeira etapa do processo de reparação tecidual é constituída pelas fases humoral e celular, que corresponde à etapa inflamatória da lesão. Tem início logo após o trauma e em feridas não complicadas por infecção, dura de um a quatro dias. $\mathrm{O}$ estímulo que deflagra o processo de cicatrização é a lesão do endotélio vascular, com exposição de fibras subendoteliais de colágeno que promovem agregação e ativação plaquetária. O contato entre colágeno e plaquetas assim como a presença de trombina, fibronectina e seus fragmentos, resultam na liberação de citocinas e fatores do crescimento. O coágulo de fibrina formado localmente funciona como molde para as células, como neutrófilos, monócitos, fibroblastos e células endoteliais ${ }^{4}$. A ativação destes elementos celulares tem implicações fundamentais em vários aspectos da cicatrização das feridas, como desbridamento, síntese do óxido nítrico e angiogênese ${ }^{5}$.

$\mathrm{Na}$ segunda etapa, fase de fibroplasia ou proliferativa, distinguem-se a reparação do tecido conjuntivo e do epitélio. Nesta reparação ocorre a formação do tecido de granulação, sendo sua principal característica a presença de fibroblastos. Estes têm participação importante, pois apresentam capacidade de síntese protéica e multiplicação celular, produzindo substância fundamental e colágeno. A epitelização se faz pelo aumento de tamanho, da divisão e da migração das células da camada basal da epiderme que recobre a área de reparação do tecido conjuntivo subjacente ${ }^{6}$.

A terceira etapa, maturação ou remodelação, apresenta dois eventos bem nítidos: o primeiro corresponde à deposição, agrupamento e remodelação do colágeno; o segundo, à regressão endotelial. Identifica-se, assim, um substrato histológico que caracteriza o tecido conectivo com fibrócitos, fibras colágenas e pequena quantidade de vasos sanguíneos ${ }^{7}$.

A remodelação da matriz e do colágeno inicia-se na formação do tecido de granulação e continua progressivamente por meses após ter ocorrido a reepitelização. Ocorre diminuição dos vasos de neoformação, assim como dos elementos celulares, inclusive dos fibroblastos. O epitélio monoestratificado transforma-se em pluriestratificado. A diminuição de todos os elementos do tecido conjuntivo ocorre de maneira progressiva até à formação de cicatriz definitiva, constituída por fibras colágenas. Esse processo é longo, e a força tênsil, que depende basicamente do colágeno, leva tempo para se desenvolver. Duas semanas, após a lesão, a cicatriz é frágil. Tem somente $5 \%$ da força normal, e vai aumentando até um ano após a lesão, mas terá sempre, no máximo, $80 \%$ da força do tecido normal ${ }^{4}$.

A reparação do tecido lesado é processo pelo qual as células destruídas são substituídas por células vivas que podem ser derivadas do parênquima ou do estroma do tecido conjuntivo lesado ${ }^{5}$. Cumpre, entretanto, salientar que tais fases da cicatrização não constituem processos isolados, mas sim apresentam dinamismo visível que, com freqüência, sobrepõe-se uma a outra, de tal sorte que numa mesma fase podem-se encontrar os elementos que compõem a subseqüente ${ }^{8}$.

Há fatores que interferem na cicatrização como a infecção, prolongando a fase inflamatória e interferindo na epitelização, contração e deposição de colágeno; a desnutrição; doenças sistêmicas; uso de drogas citotóxicas, glicocorticóides e terapia adjuvante no tratamento do câncer.

A utilização de plantas na prevenção e cura de doenças é muito antiga, data dos primórdios da civilização. Apesar da transferência de conhecimento de uma geração a outra, a maior parte das informações é fundamentada em experiências empíricas. Sua utilização, no entanto, vem sendo gradativamente regulamentada nas últimas décadas, a partir de experimentos científicos que atestam a real eficácia e sobretudo, determinam os principais efeitos colaterais. Assim as plantas medicinais têm sido integradas a um conjunto de princípios que, visam mais do que curar, restituir o homem a uma vida mais natural ${ }^{9}$.

Destaca-se nesse contexto medicinal o babaçu, palmeira do reino vegetal, classe Monocotyledoneae, da família Palmae, do gênero Orbignya, espécie Orbignya phalerata, nativo do meio-norte brasileiro, onde tem ampla distribuição geográfica $^{10}$. A maior densidade numérica é encontrada nos estados do Maranhão, Piaú, Tocantins e Mato Grosso, sendo que no Maranhão existe a maior concentração de babaçuais, distribuídos de forma descontínua em 10 milhões de hectares ${ }^{11}$.

O mesocarpo é a parte mais utilizada dos frutos, seco e moído. Ele tem sido estudado sob vários enfoques, inclusive sua ação antiinflamatória e analgésica ${ }^{12}$.

Este estudo tem por objetivo analisar comparativamente as alterações histológicas proporcionadas pelo uso do extrato aquoso da Orbignya phalerata na cicatrização de lesões cirúrgicas da bexiga.

\section{Métodos}

Este estudo foi desenvolvido no Laboratório de Pesquisas do Departamento de Fisiologia e Farmacologia do Centro de Ciências Biológicas e da Saúde da Universidade Federal do Maranhão (UFMA), São Luís - MA., e no Laboratório de Patologia do Hospital Universitário Presidente Dutra (HUUFMA. Foram obedecidas a Lei Federal nº 6.638 (1979) 
da Legislação Brasileira de Animais de Experimentação e as orientações para experimentação em animais preconizadas pelo Colégio Brasileiro de Experimentação Animal (COBEA - Resolução 592, 1992). Este estudo foi aprovado pelo Comitê de Ética em Pesquisa da UFMA

Foram utilizados 40 ratos (Rattus novergicus albinus, Rodentia mammalia), da linhagem Wistar, machos, pesando entre 135 e 300 gramas, adquiridos no Biotério da UFMA.

Os ratos foram alojados em gaiolas para cinco animais, mantidos em ciclos dia e noite em condições de temperatura e umidade ambientais, recebendo ração padrão para ratos (Purina ${ }^{\circledR}$ Labina) e água ad libitum durante sete dias para adaptação.

\section{Preparo do extrato aquoso de Orbignya phalerata}

A coleta do babaçu foi feita na área do Campus Universitário do Bacanga, em São Luís-MA, e a planta está catalogada sob número 1136 no Herbário Ática Seabra na UFMA.

O mesocarpo foi obtido a partir do coco maduro que foi assim considerado quando caindo naturalmente dos cachos.

Para retirada do mesocarpo, utilizou-se um artefato de madeira, batendo-se manualmente na parte superior até a ruptura das cascas e, em seguida, com o auxílio de uma espátula, separou-se o mesocarpo. O material obtido foi espalhado sobre uma bancada durante três dias para secar. Depois de seco, foi colocado em estufa de secagem a temperatura de $45-50^{\circ} \mathrm{C}$ durante $24 \mathrm{~h}$ para retirada total da umidade. O mesocarpo foi submetido ao processo de moagem em moinho elétrico onde se obteve um pó em forma de farinha.

Para a preparação do extrato aquoso, foi o pó pesado em balança analítica digital e diluído em solução salina para concentração de $25 \mathrm{mg} / \mathrm{mL}$.

\section{Etapas experimentais}

Os animais foram submetidos a jejum de 12 horas antes da operação. e anestesiados em uma campânula onde previamente havia sido colocado algodão umedecido em éter etílico a $97 \%$ até assumirem a posição deitada e completa imobilização. A seguir, eram pesados em balança digital e posicionados sobre um suporte de madeira em decúbito ventral com fitas elásticas. Manteve-se a anestesia com uma pequena máscara contendo algodão embebido em éter.

Com o animal anestesiado foi realizada epilação do terço inferior do abdômen e anti-sepsia. Fez-se laparotomia mediana de aproximadamente $2 \mathrm{~cm}$, em região do abdome inferior expondo-se à cavidade abdominal. A bexiga foi liberada $\mathrm{e}$, uma vez dissecada, tracionada ao exterior. Procedeu-se a sua abertura, com incisão de $1 \mathrm{~cm}$, seguida do fechamento com quatro pontos separados de poliglactina 910 em plano único total (Figura 1). Após o término do procedimento cirúrgico sobre a bexiga, os animais foram distribuídos aleatoriamente em dois grupos denominados grupo controle (GC), que recebeu dose única intraperitoneal de água destilada $1 \mathrm{~mL}$ para cada quilograma de peso do animal e grupo experimento (GE), que recebeu extrato aquoso de Orbignya phalerata, via intraperitoneal, em dose única de $50 \mathrm{mg}$ por cada quilograma de peso do animal.

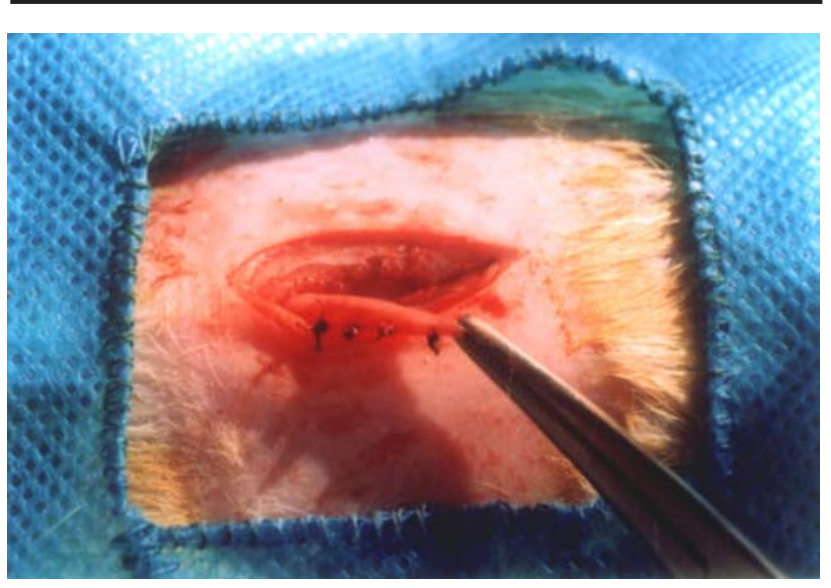

FIGURA 1 - Sutura da bexiga em pontos separados

A síntese da parede abdominal e da pele foram feitas com sutura contínua com fio de náilon 5-0.

Cada grupo foi dividido, aleatoriamente em dois subgrupos com 10 animais cada, conforme o dia da morte prevista. Os subgrupos controle 3 (SGC-3) e experimento 3 (SGE-3) foram mortos no $3^{\circ}$ dia de pós-operatório e os animais dos subgrupos controle 7 (SGC-7) e experimento 7 (SGE-7), no $7^{\circ}$. Os animais foram pesados e identificados com marcas de ácido pícrico em lugares diferentes para cada grupo.

Ao final, eles foram colocados nas suas respectivas gaiolas, identificadas com o dia a operação e o tratamento instituído.

Os animais foram examinados diariamente, anotando-se em protocolo específico o peso, as condições comportamentais e da ferida operatória. $\mathrm{Na}$ data prevista para a morte, foram pesados e colocados sob a campânula de vidro e submetidos à dose inalatória letal de éter etílico a 97\% até a ausência de reflexos.

\section{Avaliação macroscópica}

Após a morte, foram eles fixados à prancha cirúrgica e tiveram a ferida operatória examinada, assim como sua cavidade abdominal aberta, promovendo-se inventário à procura de infecções, aderências peritoneais e fístulas urinárias (Figura 2). Quando encontradas aderências, elas eram classificadas de acordo com o escore de Nair ${ }^{13}$ (Quadro 1) e a bexiga era extirpada juntamente com elas através da secção do colo vesical e, depois, aberta por incisão longitudinal na parede contrária à ferida e colocada sobre placas de isopor e presas com alfinetes para permitir melhor fixação pelo formol a $10 \%$. Os achados eram anotados na ficha protocolo e feita a documentação fotográfica padronizada para todos os animais.

Pela abertura realizada na parede abdominal, promoveuse inventário a procura de abscessos, deiscências de sutura e aderências. Observa-se na Figura 2 a bexiga ainda presa 
à cavidade abdominal pelo colo vesical e formações aderenciais grau I entre a bexiga e a vesícula seminal.

QUADRO 1 - Escore de adesão de Nair ${ }^{13}$

\begin{tabular}{|cl|}
\hline $\begin{array}{c}\text { Escore } \\
\text { (grau })\end{array}$ & \multicolumn{1}{c|}{ Achado } \\
\hline 0 & $\begin{array}{l}\text { Sem adesão } \\
\text { Adesão única entre dois órgãos ou entre um órgão } \\
\text { I }\end{array}$ \\
II a parede abdominal \\
$\begin{array}{l}\text { Duas adesões entre órgãos ou um órgão e a parede } \\
\text { abdominal }\end{array}$ \\
III $\quad \begin{array}{l}\text { Mais de duas adesões entre órgãos ou uma massa } \\
\text { de adesão generalizada do intestino sem aderir à } \\
\text { parede abdominal }\end{array}$ \\
IV $\quad \begin{array}{l}\text { Aderências generalizadas entre órgãos e a parede } \\
\text { ou aderência macica entre todos os órgãos }\end{array}$
\end{tabular}

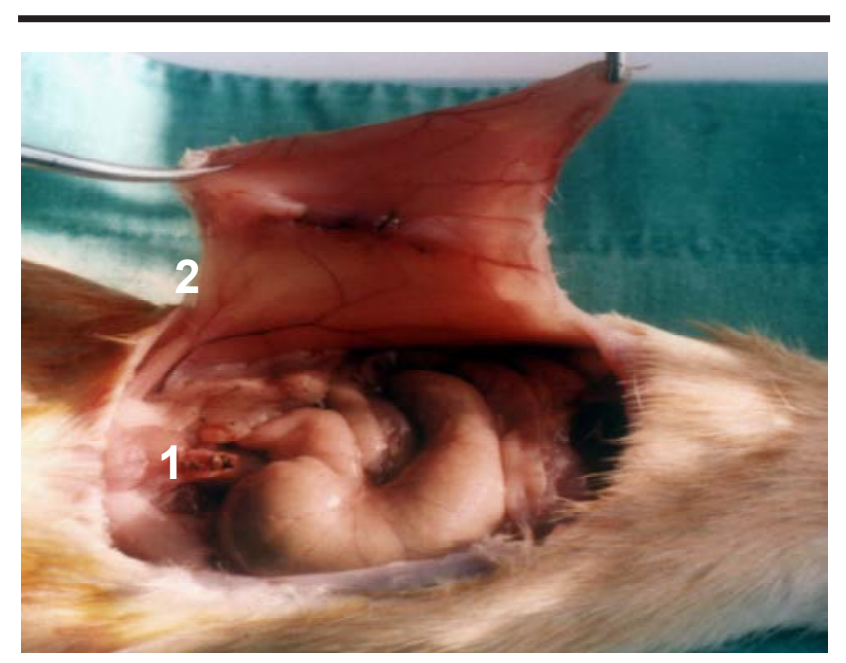

FIGURA 2 - Inventário da cavidade abdominal a procura de aderências. Nota: $1=$ Bexiga com pontos separados na cavidade abdominal; $2=$ Aderências com a vesícula seminal

\section{Avaliação microscópica}

A bexiga retirada foi fixada em formol a $10 \%$ por $48 \mathrm{~h}$, quando então foram retirados os fios de sutura e realizados dois cortes na peça, transversais à incisão, dividindo-a em três partes de $0,3 \mathrm{~cm}$ de largura contemplando as periferias $\mathrm{e}$ o centro da ferida vesical. A parte correspondente ao centro foi identificada com nanquim.

Os fragmentos sofreram preparação habitual para coloração com Hematoxilina-Eosina para verificação do processo de cicatrização e de fibroplasia e tricômio de Masson para verificação das fibras colágenas. $\mathrm{Na}$ análise, o patologista desconhecia o subgrupo do animal correspondente à lâmina estudada.

Os parâmetros histológicos analisados foram inflamação aguda, inflamação crônica, necrose isquêmica, reação gigantocelular tipo corpo estranho ao redor do fio de sutura, proliferação fibroblástica, fibrose, reepitelização, coaptação das bordas da sutura, extensão do infiltrado na parede e neo- formação capilar. Os parâmetros proliferação fibroblástica e fibrose foram também analisados nas lâminas coradas pelo tricrômio de Masson.

Os dados foram analisados estatisticamente, utilizandose o programa Statistics for Windows 5.1. As variáveis da avaliação histológica foram analisadas pelo teste não-paramétrico de Mann-Whitney. O nível de significância (p) utilizado para se rejeitar a hipótese da nulidade foi de 0,05 .

\section{Resultados}

O procedimento cirúrgico ocorreu eficientemente e todos os animais permaneceram vivos durante o ato operatório sem nenhuma complicação cirúrgica per-operatória ou anestésica.

\section{Avaliação macroscópica}

No subgrupo experimento de três dias (SGE-3), observou-se deiscência parcial da ferida operatória em dois animais. A necrópsia evidenciou secreção amarelada na cavidade peritoneal.

No subgrupo experimento de sete dias (SGE-7) três ratos apresentaram secreção purulenta na ferida operatória. Ainda em um notou-se formação de aderências vésico-epiplóica grau III. No subgrupo controle de três dias (SGC-3) notou-se ferida operatória com secreção amarelada em dois animais.

O fechamento da bexiga foi satisfatório na quase totalidade dos animais, pois em somente um rato do subgrupo experimento (SGE-3) havia secreção amarelada na cavidade abdominal decorrente de deiscência da sutura.

A Tabela 1 relaciona os achados das aderências entre os subgrupos GC e GE

TABELA 1 - Incidência de aderências segundo escore de adesão de Nair ${ }^{13}$

\begin{tabular}{ccccc}
\hline Escore de Nair & SGE $_{2}$ & SGC $_{2}$ & SGE $_{7}$ & SGC $_{7}$ \\
\hline 0 & 3 & 3 & 3 & - \\
1 & 5 & 5 & 4 & 5 \\
2 & 1 & 2 & 3 & 5 \\
3 & - & - & - & - \\
4 & - & - & - & - \\
\hline Total & $\mathbf{9}$ & $\mathbf{1 0}$ & $\mathbf{1 0}$ & $\mathbf{1 0}$ \\
\hline
\end{tabular}

A comparação da freqüência das aderências da bexiga à parede e aos órgãos intra-abdominais não revelou diferença significante em nenhum dos grupos quando feita a análise comparativa.

Houve um óbito no subgrupo experimento (SGE-3) no $3^{\circ}$ dia do pós-operatório. A necrópsia evidenciou secreção amarelada na cavidade peritoneal. Ocorreu formação de cálculo no interior da bexiga em um animal do subgrupo experimento (SGE-7). 


\section{Avaliação microscópica}

A Tabela 2 evidencia os resultados das variáveis histológicas no $3^{\circ}$ dia entre os grupos $\mathrm{GC}$ e GE.

Quanto à análise microscópica, houve diferença significativa nas variáveis neoformação capilar e proliferação fibroblástica entre os grupos GC e GE no $3^{\circ}$ dia de pósoperatório.

A proliferação fibroblástica foi mais evidente e com significância estatística o GC que no GE.

Observando-se a reação inflamatória aguda das túnicas serosa e muscular da bexiga dos ratos mortos, os números são superponíveis não mostrando diferença no teste estatístico

A Tabela 3 mostra os resultados das variáveis histológicas do $7^{\circ}$ dia entre os grupos GC e GE.

No grupo sete dias observou-se que as variáveis inflamação aguda, inflamação crônica e proliferação fibroblástica apresentaram significância estatística, sendo bem evidente a inflamação aguda no GC, notando-se também que as variáveis colagenização e coaptação apresentam-se com significância estatística marginal.

\section{Discussão}

A seleção do material de sutura merece algumas considerações. Ela deve manter sua força tênsil até que a cicatrização ocorra, e no trato urinário deve ser totalmente absorvida evitando a formação de cálculos. Escolheu-se para este estudo o fio de poliglactina 910 por ser sintético, monofilamentar, absorvível, ter perda de força tênsil previsível e sua absorção realizar-se por hidrólise ${ }^{14}$. Questão importante diz respeito ao manuseio do fio. A facilidade que o cirurgião encontra para realizar a sutura, isto é, sua pliabilidade, dá a ele maior conforto e segurança no ato operatório. Fios absorvíveis sintéticos monofilamentados, como o poliglactina 910 oferecem estas características.

A escolha da bexiga para este estudo, foi por promover ela síntese com pouco colágeno ${ }^{15}$, com pico no $5^{\circ}$ dia e manutenção até 70 dias, enquanto que o cólon e o estômago, por exemplo, a mantém até 120 dias. Quanto à vesicorrafia, optou-se por incisão longitudinal com visualização completa dos seus bordos para se obter ferida mais regular na sutura em plano único com pontos separados, como é habitualmente

TABELA 2 - Teste não paramétrico de Mann-Whitney para as variáveis da análise histológica do $3^{\circ}$ dia. LEGENDA: $\mathrm{GC}=$ Grupo controle. GE = Grupo experimento. $\mathrm{U}=$ Valor u de Mann-Whitney, $\mathrm{Z}=$ Valor da curva normal padrão, *p = Nível de significância.

\begin{tabular}{lccccc}
\hline Variáveis histológicas & $\mathbf{G E}$ & $\mathbf{G C}$ & $\mathbf{U}$ & $\mathbf{Z}$ & $\mathbf{p}$ \\
\hline Inflamação aguda & 111.5 & 78.5 & 33.5 & 0.939 & 0.348 \\
Inflamação crônica & 100 & 90 & 45 & 0.000 & 1.000 \\
Necrose & 104 & 86 & 41 & 0.327 & 0.744 \\
Gigantocelular & 118 & 72 & 27 & 1.470 & 0.142 \\
Neoformação capilar & 60 & 130 & 5 & -3.266 & $* 0.001$ \\
Proliferação fibroblástica & 131.5 & 58.5 & 13.5 & 2.572 & $* 0.010$ \\
Colagenização & 89.5 & 100.5 & 34.5 & -0.857 & 0.391 \\
Reepitelização & 104.5 & 85.5 & 40.5 & 0.367 & 0.713 \\
Coaptação & 100 & 90 & 45 & 0.000 & 1.000 \\
Extensão & 100 & 90 & 45 & 0.000 & 1.000 \\
\hline
\end{tabular}

TABELA 3 - Teste não paramétrico de Mann-Whitney para as variáveis da análise histológica do $7^{\circ}$ dia. LEGENDA: $\mathrm{GC}=$ Grupo Controle. $\mathrm{GE}=$ Grupo experimento. $\mathrm{U}=$ Valor u de Mann-Whitney. $\mathrm{Z}=$ Valor da curva normal padrão, $\mathrm{p}=$ Nível de significância.

\begin{tabular}{lccccc}
\hline Variáveis histológicas & GE & GC & U & Z & p \\
\hline Inflamação aguda & 150 & 60 & 5 & 3.402 & $* 0.001$ \\
Inflamação crônica & 146 & 64 & 9 & 3.099 & $* 0.002$ \\
Necrose & 100 & 110 & 45 & -0.378 & 0.705 \\
Gigantocelular & 119.5 & 90.5 & 35.5 & 1.096 & 0.273 \\
Neoformação capilar & 110 & 100 & 45 & 0.378 & 0.705 \\
Proliferação fibroblástica & 135 & 75 & 20 & 2.268 & $* 0.023$ \\
Colagenização & 130 & 80 & 25 & 1.890 & 0.059 \\
Reepitelização & 120 & 90 & 35 & 1.134 & 0.257 \\
Coaptação & 130 & 80 & 25 & 1.890 & 0.059 \\
Extensão & 105 & 105 & 50 & 0.000 & 1.000 \\
\hline
\end{tabular}


utilizada em experimentos ${ }^{16}$.

O extrato do mesocarpo de babaçu foi escolhido por ter mostrado atividade antiinflamatória e imunomoduladora em estudos farmacológicos anteriores ${ }^{12,17}$. A dose de $50 \mathrm{mg} / \mathrm{kg}$, baseou-se em trabalhos farmacológicos já realizados ${ }^{12}$, assim como a via de administração intraperitoneal, por sua facilidade e eficiência. Contudo, ainda é questionável qual seria a melhor concentração do extrato, a posologia e a via de administração. $\mathrm{O}$ uso de extrato aquoso se deve ao fato de não ter o álcool como veículo, de sorte que evitar-se-iam assim possíveis efeitos tóxicos ao sistema nervoso central.

Houve um óbito somente entre todos os animais o que reflete a segurança do método aqui empregado.

Ocorreu a formação de cálculo no interior da bexiga em um animal no $7^{\circ}$ dia do pós-operatório. Esta precocidade já é referida por outros autores Ortiz et al. $(1986)^{18}$. Em virtude da possibilidade de ocorrência de litíase em operações no trato urinário, existem trabalhos que polemizam o tipo de fio utilizado, indicando que os de polidioxanone, poliglactina e categute cromado tem boa performance e devem se os preferenciais em pesquisa. Como a epitelização ocorre já no $2^{\circ}$ dia, recobrindo o fio, não há grande reação inflamatória no tecido conjuntivo próximo à lâmina própria e este fato reduz a possibilidade de litíase local. Não há justificativa aparente no presente estudo para a formação de cálculo no $7^{\circ}$ dia de pós-operatório, visto que a ração Purina ${ }^{\circledR}$ (Labina) e o fio poliglactina 910 são amplamente utilizados em trabalhos científicos e não foi encontrado na literatura litogênese tão precoce.

Ao analisar a literatura observa-se que é muito variável o tempo decorrido entre a operação e a morte dos animais para realização desse tipo de pesquisa; no entanto, quando o foco se concentra em análise da cicatrização do trato urinário nas suas fases críticas, verifica-se que as avaliações ocorrem nos períodos mais precoces. Assim, a data da morte dos ratos foi determinada em três e sete dias baseada em estudos sobre cicatrização da bexiga e parede abdominal realizados por vários autores ${ }^{19,20}$.

De fato, para o que se propôs neste estudo, a avaliação histológica nestes períodos permite tirar conclusões.

A avaliação macroscópica externa e interna da peça operatória é freqüentemente utilizada na literatura, não havendo, porém, critérios estabelecidos para a padronização desta avaliação. As características internas analisadas no presente trabalho obedeceram ao escore de $\mathrm{Nair}^{13}$ para classificar a aderência da bexiga com outros órgãos da cavidade abdominal. Mostrou-se satisfatório, prático e exeqüível. Contudo, é subjetivo em relação ao controle de qualidade, mas é o que tem o cirurgião de melhor até o momento.

A coloração pela Hematoxilina-Eosina foi adotada por se tratar de corante universal, usado rotineiramente para avaliações em estudos histológicos e de cicatrização; é método de coloração simples e barato, adequado para quantificar e identificar os elementos celulares envolvidos no processo cicatricial. A técnica do tricrômio de Masson também foi empregada para se avaliar a fase proliferativa da cicatrização, através da quantificação de fibroblastos e da colagenização. Completa-se assim o estudo dos principais elementos que participam do processo cicatricial.
O processo de cicatrização de sutura, à semelhança do que ocorre em qualquer processo inflamatório, é acompanhado de etapas, com uma seqüência de alterações, que são observadas durante todo o período de reparação tecidual. O grau de intensidade da reação inflamatória pode ser de fundamental importância na cicatrização. Desta forma, Robbins $(2000)^{21}$ ressalta que certo grau de inflamação é necessário; contudo, reação inflamatória intensa é prejudicial, pois pode atrapalhar o adequado suprimento sanguíneo pelo comprometimento da microcirculação e ainda irá inibir a proliferação de fibroblastos.

No presente estudo foram avaliados, comparativamente, os vários parâmetros da reparação tecidual ${ }^{22}$. No $3^{\circ}$ dia de pós-operatório, observaram-se características semelhantes entre os grupos GC e GE, com exceção a dois parâmetros neoformação capilar e proliferação fibroblástica. No GE a neoformacao capilar foi mais acentuada que no grupo controle apresentando significância estatística $(\mathrm{p}=0,001)$; já no GC a proliferação fibroblástica foi mais evidente, também com significância estatística ( $\mathrm{p}=0,010)$. Essas alterações são condizentes com esta fase da cicatrização ${ }^{16}$.

No $7^{\circ}$ dia de pós-operatório houve significância estatística nas variáveis histológicas inflamação aguda $(\mathrm{p}=0,001)$ e inflamação crônica $(p=0,002)$ onde foi bem mais acentuada no GC que no GE. Este achado é consoante com outros estudos ${ }^{23}$ e que mostram a necessidade de reação inflamatória moderada para o desenvolvimento do tecido de granulação. Ainda no $7^{\circ}$ dia observou-se significância estatística na variável proliferação fibroblástica $(\mathrm{p}=0,023)$ sendo mais evidente no GC. A coaptação das bordas e a reepitelização das mucosas estavam presentes na maioria das observações, fato este já relatado na literatura ${ }^{24}$.

\section{Conclusão}

Observou-se efeito favorecedor da Orbignya phalerata em nível microscópico na cicatrização de feridas provocadas na bexiga de ratos.

\section{Referências}

1. Ehrlichman RJ, Seckel BR, Bryan DJ, Moschella CJ. Common complications of wound healing. Surg Clin North Am. 1991;71:1323-51.

2. Polk HC, Lopez-Mayor JF. Postoperative wound infection: a prospective study of determinant factors and prevention. Surgery. 1969; 66: 97-103.

3. Torti FM, Dieckmann B, Beutler B, Cerami A, Ringold GM. A macrophage factor inhibits adipocty gene expression: an in vitro model of cachexia. Science. 1985; 229:867-9.

4. Corsi PR, Corsi RCC, Pirana S, Muraco FAE, Jorge D. Cicatrização de feridas; Revisão da literatura. Rev Bras Cir. 1994;84:17-24.

5. Carrico TJ, Mehrhof Al Jr., Cohen IK. Biology of wound healing. Surg Clin North Am. 1984;64:721-33.

6. Kleiman I, Simões MJ, Goldemberg S. Aspectos atuais do processo de reparação tecidual. Acta Cir Bras. 1987; 
$1: 19-21$

7. Falanga V, Zitelli JA, Eaglstein WH. Wound healing. J Am Acad Dermatol. 1988; 19:519-59.

8. Modolin M. Biologia da cicatrização dos tecidos. In: Melega JM, Zanine SA, Psillakis JM, editores. Cirurgia Plástica, Reparadora e Estética. Medsi; São Paulo: 1988.

9. Matos FJA. Farmácias Vivas. 2ed. Universidade Federal do Ceará, Fortaleza, CE, 1996.

10. Joly AB. Botânica: Introdução a taxonomia vegetal. 5 .São Paulo: Nacional; 1979. p.913.

11. Zilbersztajn D. Reorganização do Agronegócio do babaçu no estado do Maranhão. São Paulo:Fundação Instituto de Administração/ USP, São Paulo; 2000.

12. Maia MBS. Estudo de atividade anti-inflamatorio e outros efeitos farmacológicos relacionados de Orbignya phalerata Mart. Fortaleza, 1987. [Dissertação-Mestrado]. Fortaleza: Universidade Federal do Ceará, Departamento de Fisiologia, 1987.

13. Nair SK, Bhat IK, Aurora AL. Role of proteolytic enzyme in the prevention of postoperative intraperitoneal adhesiond. Arch Surg. 1974; 108:849-53.

14. Edlich RF, Rodeheaver GT, Thacker JG. Considerations in the choice of sutures for wound closure of the genitourinary tract. J Urol. 1987;137:373-9.

15. Hastings JC, Van Winkle W, Barker E, Hines D, Nichols W. The effect of suture materials on healing wounds of the bladder. Surg Gynecol Obstet. 1975; 140:933-7.
16. Bartone FF, Gardner PJ, Hutson JC. Polyglactin 910 suture in urinary tract. Urol. 1977;9:521-5.

17. Barroqueiro ESB. Efeito do mesocarpo de babaçu sobre a produção de anticorpos auto-reativos.[Dissertação - Mestrado]. São Luís: Universidade Federal do Maranhão,2001

18. Ortiz V, Santos P, Osaki LT, Goldenbrg S. Sutura de bexiga em plano único, extramucoso, empregando fio inabsorvível: estudo experimental no rato. J Bras Urol. 1986; 12(4):131-3.

19. Shahan MH, Chuang AH, Brennan WA, Dirksen TR, Van Dyke TE, McPherson JC. The effect of chlorhexidine irrigation on tensile wound strength. J Periodontol. 1993; 64(8):712-9.

20. Poole Jr. GV, Meredith JW, Kon ND, Martin MB, Kawamoto EH, Myers RT. Suture technique and wound-bursting strength. Am Surg. 1984; 50(10):569-72.

21. Robbins S. Patologia estrutural e funcional. $6^{\mathrm{a}}$. Rio de janeiro: Guanabara Koogan, 2000.

22. Ramzi S. Robins basis of disease. Philadelphia. WB. Saunders.6.ed. 1999.

23. Holmes SA, James M, Whitfield HN. Potential use of tissue adhesive in urinary tract surgery. J Bras Urol. 1992; 6:647-50.

24. Nomura LM. Estudo experimental comparativo da cicatrização de sutura em cecos de ratos, utilizando os fios de polipropilene, poligrecapone 25 e glicomer 60.[Dissertação - Mestrado]. Curitiba: Instituto de Pesquisas Médicas, Faculdade Evangélica de Medicina; 1999.

\section{Correspondência:}

Conflito de interesses: nenhum Fonte de financiamento: Capes

Recebimento: 08/02/2005

Revisão: 12/06/2005

Aprovação: 16/06/2006

\section{Como citar este artigo:}

Ferreira ECF, Matias JEF, Campos ACL, Filho RT, Rocha LCA, Timi JRR, Sado HN, Sakamoto DG, Tolazzi ARD, SoaresFilho MP. Análise da cicatrização da bexiga com o uso do extrato aquoso da Orbignya phalerata (babaçu). Estudo controlado em ratos. Acta Cir Bras. [periódico na internet] 2006;21 Supl 3:33-39. Disponível em URL: http://www.scielo.br/acb

\footnotetext{
*Figuras coloridas disponíveis em www.scielo.br/acb
} 